\title{
LA GARANTÍA DEL DERECHO HUMANO A UN MEDIO AMBIENTE SANO, A TRAVÉS DEL PLURALISMO EN LATINOAMERICA
}

\author{
THE GUARANTEE OF THE HUMAN RIGHT TO A HEALTHY ENVIRONMENT THROUGH \\ PLURALISM IN LATIN AMERICA
}

\section{Marisol Anglés Hernández}

\begin{abstract}
Doctora en Derecho Ambiental, Investigadora titular de tiempo completo en el Instituto de Investigaciones Jurídicas de la Universidad Nacional Autónoma de México,

Correo: mangles@unam.mx.
\end{abstract}

\begin{abstract}
Alan David Barraza Guerrero
Egresado de la Maestría en Derecho del Programa de Posgrado de la Facultad de Derecho de la Universidad Nacional Autónoma de México, becario del Consejo Nacional de Ciencia y Tecnología, Correo: alan_bonaplin@hotmail.com.
\end{abstract}

Convidados

RESUMEN: Este artículo argumenta a favor de las teorías críticas del Derecho, con particularidad del pluralismo jurídico dentro del contexto latinoamericano; a fin de repensar los mecanismos políticos y el paradigma subyacente al marco normativo ambiental, de manera que se pondere la diversidad plural característica de la región para la construcción de alternativas en las que se politice al derecho, bajo una postura contrahegemónica y descolonial; a fin de identificar una ruta hacia el ecocentrismo en la reconfiguración de política pública y marco jurídico tendiente a garantizar el ejercicio efectivo del derecho a un medio ambiente sano.

Palabras Clave: Pluralismo jurídico. Ecocentrismo. Cosmopolita. Subalterno. Colonialismo.

ABSTRACT: This article contributes giving arguments in support of critical theories of law, particularly the legal pluralism in the latinamerican context; in order to rethink the political mecanism and the underlying paradigma in the envoirnomental legal contents, seeking that the plural diversity as a special characteristic of this región be prevailed in order to construct alternatives designed politicise the law under a descolonial and counter hegemonic position; all of that, should place with certainty the route it's needed to move for achieve the ecocentrism as a goal consider the reconfiguration of the politics and the legal framework tending towards guarantee the effectiveness of the human right to a healthy envoirnoment.

Keywords: Legal pluralism. Ecocentrism. Cosmopolitan. Subordinate. Colonialism

SUMÁRIO: Introducción; 1. Desarrollo teórico en torno a la ética y al pluralismo en relación con la garantía del derecho a un medio ambiente sano; 2. En defensa de los derechos colectivos; Conclusiones; Bibliografía. 


\section{INTRODUÇÃO}

El pluralismo, en su concepción filosófica, es la oposición al unitarismo determinista del materialismo y del idealismo moderno; según Wolkmer (2018) promueve la independencia y la interrelación entre realidades y principios diversos. La naturaleza del pluralismo estriba en contradecir al monismo, debido a que incluye al conjunto de fenómenos autónomos y elementos heterogéneos que no se reducen entre sí, provenientes de diversos campos sociales; parte del reconocimiento de la diversidad en la que existe multiplicidad de realidades, no sólo naturales y causales, sino de historicidad de la propia vida humana. En el aspecto cultural implica grupos étnicos con estilos de vida, idioma y costumbres distintos; sociológicamente alude al surgimiento de papeles, roles y estratos dentro de las sociedades con particularidades distintivas; en lo político implica el rechazo a la concentración del poder en un sector monolítico con tendencias hegemónicas, por tanto, constituye el punto medio entre el estatismo y el individualismo, entre Estado y grupos fragmentados y la mediación entre ambos, lo que representa la diferenciación de la particularidad, explicitada por el mismo Wolkmer (2018).

Los valores sustantivos del pluralismo son, en primer término, la autonomía: que es intrínseca a la identidad que poseen los colectivos frente al poder estatal; segundo, la descentralización: que implica el desincorporar el poder centralizado de las esferas unitarias oficiales para ponderar a las locales y fragmentadas; es decir, prioriza la inclusión mediante la participación de las bases sectoriales y se acompaña, en tercer término, del valor de localismo, que por su dimensión promueve la colaboración directa y comunitaria bajo la técnica de la acción colectiva participativa; todo ello, busca la valuación en la diversidad, como fuente de riqueza en los contenidos; a partir de los disensos, la multiplicidad y los contrastes entre grupos no atomizables entre sí; lo cual se practica por medio de la tolerancia en forma de regla de convivencia de aceptación de la peculiaridad y de la libre autodeterminación del otro.

Desde una aproximación jurídica, partimos de la concepción de que el derecho estatal monolítico y hegemónico es insuficiente ante las problemáticas ecológicas que azotan al planeta; de ahí, deriva la necesidad de introducir una aproximación epistémica desde el pluralismo jurídico, para no solo medir la efectividad aplicativa del derecho humano al medio ambiente sano, sino reconfigurar su propia concepción filosófica. En principio, es necesario clasificar a las posturas críticas dentro del marco epistemológico del Derecho Al respecto, Rodríguez Garavito señala que es posible confrontar dichas teorías con las denominadas «teorías constructivistas» y «postconstructivistas», que se encuentran dentro del positivismo jurídico. Las teorías constructivistas son anglosajonas y versan, principalmente, sobre la coherencia interna del derecho con relación a su propia estructura; analizan los aspectos propios de las normas, como su validez y vigencia, su distinción respecto de los principios y su naturaleza estructural; así como, toda la racionalidad jurídica alrededor de ello, que está fundamentada en la tradicional división de poderes de concepción liberal. Asimismo, la doctrina tradicional jurídica en su conjunto, de acuerdo con Kennedy (1999) aborda la aplicación de las normas y los criterios que devienen de ella, como la intersección y adjudicación; finalmente, también estudian lo relativo a la interpretación normativa respecto del ordenamiento jurídico que permite inferir, si es o no neutral su aplicación, lo que nos llevaría a conocer el grado de indeterminación del derecho, a partir de las tensiones sociales adyacentes, por una parte; así como, su formalidad lógica, por la otra.

En el caso específico de América Latina, debido al reconocimiento y aplicación del sistema jurídico romano germánico -impuesto mediante el proceso de colonización-, las teorías críticas del derecho han sido abordadas escasamente, pero cada vez, con mayor fuerza. Pues esta corriente se muestra como un campo fértil, debido a la multiculturalidad que caracteriza a la región y al reclamo contundente de la otredad, respecto de formas alternativas a los sistemas jurídicos y al paradigma tradicional del Derecho. 
Una de las características de los estudios críticos es que están guiados por cuestionamientos relacionados con la eliminación de las líneas limítrofes imaginarias impuestas por la ciencia moderna y la tradición epistemológica que busca la especialización constante, en la que se pretende aislar al derecho del resto de las ciencias sociales; dicha transformación pretende abrir canales que acopien herramientas de investigación en el derecho de carácter social con rigor analítico y métodos de corte empírico y no sólo dogmático, a fin de fomentar ideas emancipadoras dentro y fuera del campo jurídico, en búsqueda de una sociedad más igualitaria y justa, fuera de ese bagaje abstracto eurocéntrico que no corresponde a la particular realidad latina, tal como lo señalan Rodríguez y García (2003).

De acuerdo con Rodríguez y García (2011), la opresión vivida en la región latinoamericana dio paso al surgimiento de mentalidades incumplidoras de la norma impuesta, que como tal, genera ineficiencia en la aplicación del Derecho; esas mentalidades desobedientes atienden a razones culturales, en búsqueda de la superioridad moral de justicia, mediante valores y, en su caso políticas, en defensa de una posición de clase o, por razón meramente estratégica, a partir de la conveniencia subjetiva. Es así que los temas abordados por los estudios críticos en esta región, según la caracterización propuesta por estudiosos latinos, son: "el pluralismo, la ineficiencia instrumental del Derecho y el autoritarismo" (RODRÍGUEZ Y GARCÍA VILLEGAS, 2003, p. 18).

De lo anterior, se entiende que la pluralidad referida como rasgo latino tiene que ver con la existencia de diversos campos jurídicos de índole estatal y no estatal en un mismo espacio y tiempo, los cuales convergen y, por lo general, colisionan entre sí. En este contexto, la ineficiencia instrumental estriba en la diferencia entre lo establecido por el derecho y la conducta de los actores inmersos en el campo jurídico y la ciudadanía, en general, debido a la amplia brecha entre norma y práctica; el autoritarismo tiene que ver con "el uso desmedido y frecuentemente excesivo de la fuerza pública bajo el empleo de medios autocráticos o el uso sistemático de mecanismos excepcionales para imponer el derecho en las naciones donde impera la dominación colonial" (RODRÍGUEZ Y GARCÍA VILLEGAS, 2003, p. 23).

Señalan Rodríguez y García Villegas (2003), que la incorporación histórica de un campo jurídico europeo románico-germánico con características revolucionarias liberales, procedente de acontecimientos inspirados en la ilustración francesa de carácter puramente abstracto, en América Latina tuvo errores como: su insustancial incidencia dentro de las estructuras sociales americanas; el autoritarismo como herramienta de imposición contra la desobediencia colonial; así como, la utilización desmedida de mecanismos de modificación del derecho con formas y reformas empleadas sólo para legitimación institucional y no para atención eficiente de los problemas sociales, toto ello creó una superposición confusa de un campo sobre el otro (campo europeo sobre campo nativo o indiano), con base en un autoritarismo conservador, aunque con pretensiones emancipadoras, de corte dogmático religioso.

Ahora bien, en la actualidad dichos fenómenos característicos del contexto latino se presentan de distintas formas: la ineficiencia y autoritarismo se observan en la heterogeneidad y descomprensión de los sectores económicos que pertenecen masivamente a la informalidad; ya que, la ineficiencia provoca mayor distanciamiento de los sujetos que se resisten al sometimiento de la estructura estatista formalizada, lo que genera desarticulación entre el poder central y las bases sociales difuminadas, las que, por su parte, crean autonomías relativas que debilitan el poder hegemónico del Estado; el déficit político que obliga a los gobiernos a recurrir al derecho por medio de textos legales (RODRÍGUEZ y GARCÍA, 2003); no obstante, esta incipiente democratización se desarrolla en condiciones de extrema contradicción; por un lado el esfuerzo, al menos discursivo, por ensanchar las libertades públicas, el bienestar social y, entre otras, la justicia social -vista y pensada desde la alteridad- y, por el otro, la permanencia y recrudecimiento de la pobreza, discriminación, desigualdad, exclusión y violencia (ANGLÉS, 2014a, p. 267). Asimismo, la ineficacia instrumental de dichos contenidos legales se debe a que el enfoque se atomiza a sectores 
específicos; olvidándose el problema real, el cual es atenuado por el alcance de los derechos mediante la excepción jurídica.

Por otro lado, de acuerdo con Wolkmer (2018), en Latinoamérica se puede apreciar el pluralismo jurídico a partir de datos empíricos y fenómenos como: la justicia informal, popular o alternativa; el derecho consuetudinario y la justicia indígena; así como, el constitucionalismo andino; este último desarrollado por diversos autores debido al surgimiento en los hechos de constituciones inspiradas en el pluralismo, que emergen vía las normas fundamentales en un proceso integracionista, mediante la constitucionalización de derechos provenientes de los movimientos indígenas de la región latinoamericana de los Andes; que, de acuerdo con Raquel Yrigoyen (2006), expande y adapta el garantismo a la realidad regional de la diversidad, a partir del constitucionalismo social.

\section{DESARROLLO TEÓRICO EN TORNO A LA ÉTICA Y AL PLURALISMO EN RELACIÓN CON LA GARANTÍA DEL DERECHO A UN MEDIO AMBIENTE SANO}

Como resultado de la degradación ambiental global imperante, las naciones desarrolladas comenzaron a indagar sobre principios que conjuntaran, por un lado, la problemática sobre la contaminación ambiental y la sobreexplotación de recursos y, por el otro, los retos sociales, políticos y económicos que implican la pobreza, desigualdad, justicia social e inseguridad, de manera que pudiera conciliarse el concepto humanizado de bienestar con la figura de desarrollo, todo frente a la necesaria consideración de las condiciones ambientales, como elemento determinante. De acuerdo con Kwiatkowska (2009), ello significa conciliar todos los factores humanos de lo social y económico con lo ecológico en un marco de interdependencia, que a ultranza se denominó sustentabilidad; integrada, según Capra (2003, p. 25), por: "Una red compleja de relaciones que implica a la comunidad como un todo. Una comunidad humana sostenible interactúa con otros sistemas vivos -humanos y no humanos-, de tal modo que les permite vivir y desarrollarse según su propia naturaleza".

Esto constituye el albor de la creación de una ética fuera del monismo humanista totalizante, plasmada en objetivos concretos que modifican la concepción instrumental del entorno natural y de todo lo que anteriormente se daba por sentado respecto de él, como su inagotabilidad. Al respecto, cabe señalar que las teorías clásicas de la economía política conciben al crecimiento incesante como sinónimo de desarrollo; sin embargo, la agotabilidad contraviene esa posición; en respuesta, el economista Joan Martínez Alier (1987) refiere con claridad el principio moral de Ramsey, que alude a la cuota de sacrificio de los recursos, en cuanto al consumo actual en relación con el futuro; lo cual, constituye una tasa de descuento que nunca se contempla, pues se supone un futuro próspero per se. Lo que subyace aquí es la base de los conflictos de asignación de recursos a escala intergeneracional; pues, si se sale del discurso cerrado de la economía del crecimiento y se entra en la economía de los recursos agotables, entonces no se puede saber si el futuro será más o menos próspero que el presente.

La complejidad de la situación actual en torno al estado del medio ambiente demanda modelos críticos de solución radical, pues muestra claramente que, como especie, no hemos sabido coexistir en este planeta, ni afrontar la axiomática finitud de la biosfera; pues como refiere con puntualidad Riechmann (2016, p. 79) "ha imperado un modelo de bienestar en forma socioeconómica de expansión continua, deficiente y autodestructiva" que, a la luz del sistema capitalista neoliberal sólo valora el ingreso y la competencia, en virtud de que su principio fundamental es la obtención de riqueza individual, lo cual demanda perdedores frente a ganadores y en esa relación únicamente se persigue, como meta, la preservación del status quo; por consiguiente, como sistema pasa a ser el principal lastre que imposibilita el cambio de paradigma hacia un tipo de ética ecocéntrica que viabilice la sustentabilidad. 
Al respecto existe una alternativa teórica dentro del pensamiento marxista, que consiste en una crítica dialéctica del materialismo histórico en contra del capital y de su empleo como valor de cambio universal, movido por el libertarismo individual; esa amplia doctrina denominada ecosocialismo, que no será abordada con detenimiento en este estudio, se muestra como una corriente crítica contra la catástrofe ambiental de la actualidad y en ella encajan todas las proposiciones teóricas contrarias a la ideología de progresismo lineal, productivista y consumista. El ecosocialismo también reta al tecnicismo cientificista de dominio de la naturaleza, como conducto al desarrollo humano y, en su lugar, busca el predominio de la relación humanonaturaleza, extraída de autores como Lowy (2012).

Dicha corriente se basa, por una parte, en el socialismo, al romper lazos con el productivismo de mercado de los movimientos obreros tradicionales para entender que la relación de beneficio y poder debe emerger desde una perspectiva ecológica y, por otra, critica las posturas del ecologismo radical que equiparan en un plano de igualdad integral a todos en el medio biótico, por lo que busca un punto ecléctico entre ambas corrientes críticas, sin perder de vista el fundamento de ruptura con el productivismo, como sinónimo de progreso, al establecer canales de oposición a un modelo de expansión ilimitado de producción y consumo cíclicos.

Puede observarse, que dichos parámetros denotan más allá del aspecto ético, una noción sociopolítica muy marcada que es pertinente mencionar e incluir dentro del contexto de elaboración en filosofía moral de un paradigma ecologista, como el que plantea Baird Callicot (1998), en cuanto al ecocentrismo comunitarista de extensión holística, debido a que propone, de forma adyacente, cambios radicales del panorama social y político; así entonces, esta corriente considera de forma acentuada los valores democráticos comunitaristas, respecto de la propia concepción anti individualista de la propiedad y la disminución de la brecha de desigualdad y la injusticia social, que se traducen en el aprovechamiento asimétrico de recursos.

Ahora bien, aunque la finalidad de esta contribución no es atacar de manera depurada y frontal al sistema capitalista, es preciso mencionar que no podría existir una postura crítica ecológica y de pluralidad multicultural que esté a favor, y conciba como un camino viable al capitalismo verde; pues éste pretende adecuar los fundamentos ideológicos del capitalismo productivista al ecologismo, sin considerar que son precisamente esos ideales de crecimiento lineal los que generaron el estado crítico en el que nos encontramos. Así entonces, desde la óptica del mismo Callicot (1998) es momento de referir los grandes espectros de la ética ecológica; los cuales, pueden clasificarse en quienes ubican al medio ambiente en un lugar instrumental y, en los ecologistas, quienes, a su vez, se subdividen en los partidarios de la ecología profunda (que desde un esencialismo metafísico diluyen el yo con el entorno natural con base en el amor hacia sí mismo expandido a todo el entorno y los seres vivos); y los ecofeministas, que equiparan a la dominación opresiva histórica patriarcal, con el dominio humano de la naturaleza y el medio ambiente.

Dentro del espectro ecológico se ubica el bloque ecocéntrico, que también es conocido como extensionismo ecológico; mismo que se subdivide en tres etapas o fases de evolución: primero, el ecologismo en relación con los problemas ambientales concretos, en el que se clasifica cada aspecto ambiental de manera aislada y jerarquizada, dentro de esta corriente se coloca a la ética de la liberación por los derechos animales, en las figuras de Singer (1999) y Regan (2007), quienes conciben el problema de respeto moral por los animales, como prioridad ética.

La segunda etapa es conocida como el biocentrismo, y es la que pugna por la consideración de valor a todo ente vivo de manera inherente e igualitaria; es decir, a diferencia de la primera etapa de problemas ambientales concretos, ésta rompe con la jerarquización valorativa. Y finalmente, el extensionismo comunitarista de conexión ecológica, en la figura del mismo Callicott y Leopold (1998), bajo el argumento "ética de la tierra"; ellos defienden una visión holista integradora de todos los medios, sistemas y subsistemas de la naturaleza, incluido el ser humano, que propone, básicamente, desde el aspecto colectivo, el acrecentamiento de la comunidad biótica en su integridad y, desde el individual humano, la restricción y moderación. 
La corriente más aceptada por los pensadores y filósofos ambientales es la del extensionismo comunitarista de conexión ecológica, pues abarca los recovecos de criterios que pudieran ser criticados; como el argumento que reputa de individualista y atomista a la postura extensionista de problemáticas ambientales en concreto, que defiende la liberación y derechos animales, aseveración que es lapidaria dentro de una visión ecológica, debido a que, por principio conceptual, la ecología debe ser colectivista por lo que hace a dicha corriente más obstáculo que medio; ya que, no considera al entorno en su conjunto de forma holística, como objeto de protección; además, como refiere Kwiatkowska (2009, p. 23) "desatiende una de las causas principales de extinción de la biodiversidad, que es la devastación de los ecosistemas".

Por su parte, en el desarrollo referencial crítico, Callicot (1998) menciona que la ecología profunda tiene un carácter ilusorio que la aleja de la practicabilidad, debido a que refundan categóricamente cualquier concepción existencialista humana del sí mismo y del exterior de manera artificial en busca de la autorrealización conjuntiva; de la misma forma, el ecofeminismo, por ser sustitución ateórica, sólo reforzaría los patrones de dominación opresivos, debido a la misma imposición conceptual de dimensiones distintas; en general, ambas coartarían cualquier resquicio de tolerancia y valoración democrática, ya que, imponen una cosmovisión a priori.

Ahora bien, es necesario considerar que la elaboración de fundamentos completos y definitivos sobre la necesidad de valorizar a la ecología en sus medios y sistemas biológicos y abióticos; así como, al medio ambiente en su calidad de entorno espacial es difícil, debido a la misma complejidad e incertidumbre de la totalidad que comprende la naturaleza y sus interacciones, por lo que se entorpece la existencia de un modelo fijo. Así entonces, es ahí donde la construcción y búsqueda de justificaciones conservacionistas recaen en la ética, por valores intrínsecos de carácter moral y no por un criterio científico riguroso susceptible de falsación, errores y vaguedad.

Con base en lo anterior, se admite entonces la necesidad de la búsqueda igualitaria de justicia conforme a la diversidad y consideración paritaria de la otredad. Ello demanda la congruencia con lo "comunitarista" que, desde el plano antropológico, en contraste con el medio natural, en la visión de Riechmann (2016), implica la cooperación igualitaria, como simetría práctica de consideraciones recíprocas; por tanto, se sugiere que sea desde el comunitarismo biótico, que atribuye valor a las entidades por su valor holístico, independientemente si sus componentes son humanos o no, sin el requerimiento de tener completa certidumbre científica de todo el entorno natural.

Cabe señalar que la ética ambiental perteneciente al ecocentrismo de las etapas antes mencionadas no empata con la ética tradicional humanista; por ejemplo, el antropocentrismo moderado, aunque tenga un nivel de consideración de la vida y del medio natural más allá del ser humano, como refiere Nava (2013), no deja de instrumentalizar al medio ambiente en función de la vida y el bienestar humanos, ya sea desde el tecnocentrismo-ambientalista o del marxismo, aunque reconozca la evidente crisis ambiental de manera moderada. En definitiva, las corrientes adscritas al bloque antropocentrista, aunque son moderadas por su consideración ambientalista, no aportan una visión renovada, innovadora y trasformadora que solucione la crisis ambiental, en virtud de que siguen el mismo método lineal, que apuesta por el reformismo y la concienciación desde lo global y en una posición individual capitalista que conduce al mismo resultado tautológico; respecto del combate a la crisis ambiental, la preservación del equilibrio ecológico, la búsqueda de justicia distributiva social y el respeto considerado por la pluralidad; por lo que optamos por la visión ecocéntrica de extensionismo comunitarista, al menos de manera inicial y a reserva del proceso dialógico de la praxis jurídica y política.

La cuestión de la garantía del derecho humano a un medio ambiente sano depende, en principio, de la protección medioambiental efectiva, ya que, es el elemento sine qua non para materializar tal derecho. Empero, generalmente, este derecho humano pareciera partir de una valoración axiológica antropocéntrica, asociada a la salud y aprovechamiento de recursos por parte 
de los seres humanos, con una aproximación utilitarista valorada a partir del beneficio humano; no obstante, se estima que su conceptualización es constructiva y, de inicio, debemos partir de ese derecho por estar ya reconocido, a reserva de su desarrollo nominal, con base en la transición a una ética pura, ecológica, holística y extensiva. La configuración patente humanista y en conexión directa con la salud humana, como aún hasta ahora está estructurado el derecho humano a un medio ambiente sano, es de por sí compleja. Por ello, en la transición de paradigma ético renovador, hay que partir con cautela, pero de manera firme determinar las bases para avanzar hacia una ética ambiental específica y delimitada, en permanente reconstrucción.

Ahora bien, la emergencia de una ética ecocéntrica comunitarista debe acompañarse del enfoque teórico pluralista, no sólo desde la arena jurídica, sino también política; ya que, a diferencia del ámbito jurídico, la política centra su atención en el poder y sobre éste. De forma general, Forero (2011) enuncia todas las corrientes teóricas que explican el enfoque del pluralismo político y establecen su desarrollo epistemológico alrededor de elementos, como: la existencia de diversos grupos dotados de poder y la correspondiente inexistencia de un centro único; la paridad coexistente de grupos potenciados que impide la acumulación del poder por uno de ellos y, la compensación recíproca entre dichos grupos, por medio de la solidaridad cruzada que impide la sobrecarga del sistema político.

Ello implica que el pluralismo político opera como una suerte de peso y contra peso intergrupal, a través de mecanismos jurídicos y políticos, en un modelo en el que, si uno de ellos sobrepasa su concentración de poder se le restringe, a fin de restablecer el equilibrio pluralista. La relevancia de incluir lo político en el pluralismo jurídico es sustancial; ya que, lo social oscila entre ambos y la función última es la solución de conflictos de índole social; a causa de ello, Wolkmer (2018, p. 205) en su nuevo paradigma pluralista insiste en la inclusión de ambos enfoques (jurídico y político) en forma de fundamentos de efectividad formales y materiales, organizados en una propuesta práctico-teórica con visión crítica.

En el mismo orden de ideas, Forero (2011) refiere que la pluralidad, como fundamento filosófico, es la condición para la acción; aunque, en ese proceso cohabitemos en convergencia en el mismo espacio planetario no somos todos iguales; por lo que la afirmación positiva de la desigualdad es condicionante de la acción por la distinción identitaria; particularmente, de la acción política y jurídica. Esa concepción enfoca al pluralismo en la acción por parte del "quién" en "sí mismo" para o por "el otro", a fin de trascender a la mera subjetividad natural corpórea y la tautología de la mismidad autoevidente que implica la mera dimensión biológica. En conclusión, la comunidad política es la creación de la agrupación de espectadores que, en su conjunto y a partir de su cohabitar, emergen a la esfera pública y que gracias a la pluralidad de sus actores nace la acción que identifica al otro, que crea lo que concebimos como realidad. ${ }^{1}$

En otro sentido, al apreciar los datos empíricos existentes sobre la humanidad desde la filosofía, se advierte la pluralidad; pues la diversidad es característica intrínseca de nuestra especie, desde ese plano de entendimiento no hay discusión al respecto; el problema nace en su incorporación a las disciplinas sociales y con ello a la realidad fáctica. Un ejemplo de esto es la obstinada noción de igualdad formal en abstracto, no obstante las asimetrías históricas por dominación colonial del norte respecto de naciones del sur; lo cual, acaece mediante la distribución del poder que se dio de afuera hacia adentro y desde lo global hacia lo local, debido a que un sector de la población mestiza impulsó la adopción del sistema económico estadounidense, que como señalan Dezaly y Garth (2005), fue impuesto como instrumento monolítico hacia el desarrollo, a partir del Consenso de Washington, en los territorios latinoamericanos como sello de progreso, de la mano de avances tecnológicos provenientes de la modernidad occidental.

\footnotetext{
${ }^{1}$ El planteamiento de Forero tiene inspiración en la ética pluralista de la filósofa alemana Hanna Arendt, en cuanto a que opta por la acción como fundamento ontológico de la ética aplicada a la política, que es una vía trascendente para aplicar de manera pragmática los principios axiológicos, como el mismo respeto por la otredad y la solidaridad en lo social.
} 
Así, en Latinoamérica, los grupos tecnócratas que emergieron del mencionado proceso recolonial o de colonialidad interna emplearon una táctica de segmentación de los sectores sociales y comunidades multiculturales, ello mediante el modelo Estado-nación, apuntalado en la centralización de la política y el derecho y, como resultado, en la homogeneización cultural forzada e ignorancia de regímenes jurídicos diferenciados (ANGLÉS, LEYVA y RUIZ, 2017, p. 66) ignorándose cualquier noción plural. Cabe señalar que el modelo económico estadounidense, carente de un enfoque sustentable e incluyente, contribuyó al incremento de la problemática ambiental y al aumento de la discriminación y exclusión social (ANGLÉS, 2015).

En referencia a los Estados Unidos de América, Mignolo (2000) recuerda que esta nación, distanciada de la América nativa y de la correspondiente ascendencia latina, se apartó del bloque geo-cultural del resto del continente, a partir del corolario de Roosevelt, a finales del siglo XIX, al incorporarse al hemisferio occidental/moderno, como forma de triunfo en el nuevo orden mundial en un auto valorado estado neocolonial; de tal suerte que, desde su papel hegemónico occidentalista eurocéntrico se autoproclamó como la única América.

Así, a manera de compensación, en un primer momento, otorgó a las naciones explotadas por su hegemonía, una retórica declarativa de búsqueda de la homogénea internalización de los derechos humanos; no obstante, todo el proceso previo de desarrollo economicista unilateral denuncia total contradicción. Según Dezaly y Garth (2005), señalan que hubo doctrinarios de la política y el derecho que refirieron, entre los años sesenta y setenta, que los derechos humanos en la óptica estadounidense no son derecho, sino mera política.

Es por ello que, el pluralismo aplicado debe considerar a la sociología de las emergencias de Boaventura de Sousa (2010) en su planteamiento de refundación del Estado latino; ya que consiste en la investigación de las alternativas concretas que se encuentran en la potencialidad y posibilidad de lo que todavía no ha emergido, pero puede aparecer; tiene un carácter simbólico y consiste en ampliar, con esperanza al porvenir, el marco de posibilidades bajo la mecánica axiológica del cuidado; llevado a la praxis, es semejante al paso progresivo en América Latina del constitucionalismo: que fue del multicultural en los ochenta, al pluricultural en los noventa, hasta llegar al más reciente constitucionalismo plurinacional en 2008 y 2009, advertido en los casos ecuatoriano y boliviano (YRIGOYEN, 2011).

Una alternativa sería, invertir el orden jerárquico de la hegemonía colonial monista, ordenada desde arriba y a partir de las élites cupulares; para incorporar desde abajo a las sociedades dentro del pluralismo democrático participativo y desde la comunidad como ente local, como sujeto jurídico autónomo. De forma que, se afirme y emplee el esquema multidisciplinario que recupera el cosmopolitismo con pluralismo jurídico y político desde lo subalterno desarrollado, tal como apuntan Rodríguez y De Sousa (2005) en la denominada interlegalidad cosmopolita subalterna; que, al ser un enfoque horizontal universalista, aporta instrumentos analíticos e insumos o principios epistémicos que se fundamentan en la idea de cosmopolitismo, el cual es ignorado por el Estado-nación, pues debido a su centralidad adolece en su base moral de auténtico y efectivo respeto por la alteridad.

Dado que los proyectos cosmopolitas, tradicionalmente, tienen un diseño de globalidad que invisibiliza los elementos y paradigmas axiológicos inherentes a los derechos humanos, tales como dignidad, igualdad o justicia de culturas o grupos ajenos a la modernidad occidental del hemisferio norte dominante; se propone invertir el concepto cosmopolita para ponderar a las víctimas de la hegemonía desde la legalidad y el orden jurídico; a fin de restablecer su conexión con el universo político, por medio de las instituciones que permitan la construcción de la estructura desde abajo; lo cual, afecta notablemente los intereses de grupos enraizados en una posición de privilegio, reforzada por la globalización en lo jurídico, como el litigio estratégico transnacional o el lobbying (RODRÍGUEZ y DE SOUSA, 2005, p. 15), consistente en el cabildeo en las altas esferas políticas de las naciones desarrolladas. 
En esa escena global, los intereses son multitudinarios y atienden a un incontable número de perspectivas que confluyen en la globalización, como una red que funciona al ritmo dictado por la economía liberal; en el campo jurídico el enfoque es sobre la producción normativa, más que respecto de las disputas y encuentros litigiosos. En ese escenario, la red global influye en las esferas nacionales de poder, respecto de la producción normativa para que se legisle de conformidad con sus intereses; lo cual, es perpetrado por instituciones diseñadas para tal propósito, que ejecutan su estrategia al llevar desde su nicho global las directrices hacia el ámbito local, en conatos específicos de poder y significación, hecho por medio de análisis etnográfico y sociológico, para trasladar cada contexto a una arena de derecho común; esto es, "el reformismo del law without the state" (LEMAITRE, 2015, p. 437) que apunta hacia la desregulación o autorregulación de los organismos trasnacionales frente a los diversos aparatos estatales.

Por otra parte, es factor de consenso entre los juristas que lo que hace al derecho como tal, es el uso de la fuerza necesario para obligar al cumplimiento de sus disposiciones; por ello, en su ausencia desde el plano de la globalidad, en el que no hay Estado soberano que esté dotado de dicho poder, es el consentimiento de los negocios y el fruto obtenido de ellos el que opera en su suplencia; lo cual a su vez, define al derecho global que está contenido; generalmente, en una intrincada red de normas no obligatorias del denominado derecho blando (soft law), fenómeno que, según Lemaitre (2015), en el caso de los derechos humanos, particularmente, en los países neocoloniales, provoca que dichos derechos se tergiversen por su propio fin.

Por otro lado, el recorte de la presencia del Estado dado a partir de los años setenta, con base en la modificación del paradigma político, resultado de la desaceleración de la producción económica tradicional del modelo fordiano, ha provocado erosión en la legitimidad política y el resurgimiento de formas de violencia privada; que bajo el ideal de liberalización y desmantelamiento de lo público ha generado crisis en casi todos los rubros que atañen al ámbito público, máxime que lo político se ha disipado frente a la economía en el esquema de globalización. Como ejemplo, Rodríguez (2012) alude a los campos sociales minados en Latinoamérica, justamente, en los que hay disputas violentas permanentes entre sectores sociales y culturales por el territorio, los recursos y/o la identidad indígena; lo paradójico, es que, según Anglés, García y López (2020), una de las salidas al conflicto se da al amparo del ejercicio del derecho a la consulta indígena, como mecanismos legal de simulación que justifica la adopción de decisiones que materializan la creciente exclusión social y privilegian la imposición de los capitales, tanto nacionales como extranjeros, orientados a la extracción de recursos naturales.

De acuerdo con Alberto Ángel (2011), los entes privados potentes económica y militarmente a nivel global, son quienes rigen y ejercen el poder real, aunque siempre acompañados y respaldados de la institución política, como forma legitimadora; lo que conduce a afirmar, que, sin duda, en ese control perseguido y bajo esa la lógica de dominación bajo la que operan, la imposición monopólica desde la cúpula de una conceptualización sobre qué sistema o paradigma debe existir es, hasta cierto punto, válida; pues precisamente los entes trasnacionales privados son quienes imperan; en cambio, a la inversa la propuesta pluralista es de ponderar lo subalterno; que, se halla en la base, y no consiste en eliminar todo rastro de individualismo liberal o de autonomía personal, de hecho es la base de la concepción de los derechos en el plano subjetivo, ello sugiere introducir "el entendimiento solidario de la titularidad en los derechos, como forma alternativa" (RODRÍGUEZ Y DE SOUSA, 2005, p. 16).

La alternativa implica restablecer el equilibrio pluralista resultado de la sobrecarga de poder acumulado en un grupo de individuos dispares, por medio de la acción política y jurídica; lo que se manifiesta, en muchos casos, mediante conflictos sociales y disputas alrededor del mundo, pero con mayor notoriedad en naciones neo o recolonializadas del sur americano; asimismo, la globalización y la concepción transnacional y nacional faltan en concordancia con principios democráticos, debido a que son excluyentes, lo cual causa que los procesos democráticos de representación sean cada vez más puestos en duda, en relación con su verdadera naturaleza, alcance 
y efectividad. Por ello, los mecanismos de participación comunitarios son fundamentales, pues se basan en una ética cada vez más ecológica, con especial acentuación en el caso de la construcción de la política ambiental, encontrándose legitimidad ante la tensión de capitalismo y democracia. Así entonces, se sugiere la clasificación dimensional a escalas, de lo local a lo regional, de ahí a lo nacional y en última instancia a lo global.

\section{EN DEFENSA DE LOS DERECHOS COLECTIVOS}

En cuanto a la protección de la tierra y del medio ambiente en Latinoamérica y, por ende, a un medio ambiente sano, la constante es la búsqueda descolonial que une el pluralismo con la lucha contrahegemónica en la filosofía de la liberación, la cual, está íntimamente relacionada con los movimientos indígenas en América Latina frente a la hegemonía de globalización económica neoliberal responsable de que los indígenas sean los más pobres entre los pobres (RODRÍGUEZ y ARENAS, 2005). A fin de dimensionarlo con datos de los países con mayor densidad demográfica indígena: Para 2018, en México, el porcentaje de población indígena que se encontraba por debajo de la media de pobreza era 71.9\% (CONEVAL, 2018); en Guatemala, 80\% de la población indígena se encontraba en ese parámetro de pobreza (MDSG, 2018, p. 37); mientras que en Bolivia, $34,6 \%$ de la población total vivía en pobreza (INEEPB, 2019, p. 136). ${ }^{2}$

Los movimientos indígenas son los que más réditos han dejado en la lucha por la igualdad social estructural; pues desde lo local han buscado la autodeterminación, respeto y vindicación por el territorio, recursos naturales, formas legales, costumbres y tradiciones ancestrales; han resistido a la dominación por siglos; pero, principalmente, forman parte de movimientos globales (activismo transnacional) en defensa del medio ambiente, en cuanto tratan de resistir a la expansión explotadora de recursos para sostener el ritmo de consumo del norte respecto del sur; también han luchado por el reconocimiento de sus derechos colectivos y por la creación de instrumentos jurídicos y mecanismos políticos, que reconstruyan constitucionalmente los derechos humanos desde el cosmopolitismo (RODRÍGUEZ y ARENAS, 2005).

Al respecto, un caso notorio que involucra contaminación ambiental y degradación ecológica es el de la ciudad de Toritama en Pernambuco, Brasil; en el que desde los años setenta se dio un auge industrial en la manufactura textil que provocó la contaminación del río Capibaribe que, a su vez, afectaba el aprovechamiento del cauce y la salud de los pobladores (PORTO MACEDO, 2011).

Para atender las denuncias, la autoridad estatal de Pernambuco aplicó la legislación ambiental y creó un Programa de regularización operado por instituciones públicas y privadas, encabezadas por la Agencia Estatal de Medio Ambiente y Recursos Hídricos -la autoridad ambiental a nivel regional-, dicho Programa consistía en restringir la actividad industrial con medidas tendientes a mitigar o controlar los efectos de la contaminación. Entre las acciones se encontraba, la instalación de plantas tratadoras de agua, la realización de procedimientos de limpieza y disposición de residuos; la operación de chimeneas para reducir la emisión de gases y olores; todo ello, se tradujo en ahorro de costos a la industria por la reutilización del agua y residuos reciclados como insumos industriales (PORTO MACEDO, 2011).

El secreto del éxito en este caso fue no evadir la fiscalización; es decir, no pactar para impedir la regularización con la excusa de no soportar los gravámenes que implica corregirse, argumentando altos costos financieros para conseguirlo y con ello escudarse en la falta de "desarrollo", por la potencial pérdida de empleos e ingresos económicos, que significaría incrementar el costo de regularizarse por parte las empresas; sin embargo, la solución estuvo en la aplicación normalizada y trasversal de la normatividad de manera gradual; en la operación estatal

\footnotetext{
${ }^{2}$ Cabe referir que como en Bolivia la población que se identifica como perteneciente a un pueblo indígena originario campesino es apenas el 24,9\% hay dificultad para distinguir entre grupos étnicos, pues el indicador se da por área rural o urbana; así entonces, no es diferenciado por grupo indígena dada la proporción plurinacional de dicha nación.
}

Revista de Direito Brasileira | Florianópolis, SC | v. 27 | n. 10 | p.146-161 | Set./Dez. 2020 
más allá del mero ámbito sancionador, que desconoce el problema y sigue la literalidad de una norma abstracta, sino en la identificación de la problemática y la solución integral a la misma. De manera que, "la interpretación y aplicación del derecho se convirtió en instrumentación de gestión estratégica armónica" (PORTO MACEDO, 2011, p. 340), con un carácter notoriamente político, por el consenso conseguido en la cuenca de que el daño debía parar, lo que pasó a ser estrategia de legalidad politizada.

Ello significa, que la forma de aplicación del derecho debe ser transversal y negociada con base en criterios preestablecidos conforme al caso específico; ya que, la politización previa a ello es de orden consensual al interior de una dimensión espacial suficiente, para que el conocimiento de la problemática haga factible que el criterio de aplicación atienda causas reales y no intereses coyunturales desde arriba; en muchas ocasiones, existen otras opciones obtenidas de consensos, donde todos los actores son oídos, es la alternativa más viable respecto de la eficacia de sus propósitos, que en este caso era la preservación del medio ambiente y la salud.

Ahora bien, otro caso concreto que refieren Rodríguez y Arenas (2005) es el de la nación indígena U'wa, ubicada en el noreste de Colombia, cuyos integrantes han tenido que defender su territorio -aproximadamente 60,000 hectáreas-; desde la década de los setenta, frente a diversas empresas extranjeras y nacionales que buscan la exploración y explotación de hidrocarburos, realización de actividades turísticas y, entre otras, otorgamiento de concesiones mineras, lo que amenaza su cultura, territorio y recursos naturales. Como estrategia, la comunidad U'wa creó una asociación política por la defensa de sus derechos colectivos, logrando el reconocimiento de la titularidad de su derecho colectivo a la tierra, por parte del Estado colombiano y la creación de una reserva de 61,115 hectáreas en 1987; posteriormente, en 1991, el reconocimiento, a nivel constitucional, de los derechos particulares de los grupos indígenas en general.

Este caso representó un serio avance en el garantismo progresivo pro diversidad; sin embargo, a inicios de la misma década de los noventa, apareció en la escena nacional la empresa de hidrocarburos Oxy, aliada con la petrolera estatal colombiana Ecopetrol y la estadounidense Shell, quien buscó explorar y posteriormente explotar yacimientos de petróleo en parte del territorio U'wa. Dichas corporaciones transnacionales e, incluso, la nacional obtuvieron permisos ambientales y subcontrataron personal, para hacer pruebas geológicas en la zona, pero el pueblo indígena se opuso a cualquier actividad y proyecto de manera tajante; no obstante, las empresas ganaron los fallos en las instancias administrativas, por lo que el proyecto se aprobó sin demora.

Esto representó, desde el comienzo, un revés contra la autonomía y los derechos comunitarios del pueblo indígena; por lo que la comunidad invocó ante la autoridad nacional los derechos constitucionales recién adquiridos y los mandatos del Convenio 169 de la Organización Internacional del Trabajo sobre Pueblos Indígenas y Tribales en Países Independientes (Convenio 169), en relación con su derecho a ser consultados de manera previa, lo que causó el advenimiento entre representantes U'wa y las empresas petroleras. Como resultado de las reuniones para resolver el conflicto, quedó de manifiesto la ignorancia del gobierno y las empresas respecto del derecho a participar en el proceso por parte de la comunidad, aunque ello no significó ningún logro a favor de los U’wa; en virtud de ello, en 1995 el Ministerio de Medio Ambiente volvió a aprobar la licencia de exploración, al argüir que mediante las reuniones con la comunidad habían cumplido el requisito constitucional de consultarles.

Este atropello detonó la intervención de redes de abogacía transnacionales y organizaciones no gubernamentales ambientalistas de alcance internacional y, en conjunto, formaron la Coalición trasnacional en la defensa de la comunidad U’wa; que utilizó, simultáneamente, la ruta política y jurídica, lo que llevó la lucha a una dimensión multilateral, que pasó de lo local a lo global, con acción directa, incluso, en la arena mediática en contra de la empresa Oxy, quien en 2001 se desistió de cualquier proyecto en el territorio indígena U'wa. No obstante, el asedio a la comunidad por la riqueza que se halla en sus territorios ha continuado de forma incesante, por ello, en 2014 la nación indígena U’wa presentó una petición ante la Comisión 
Interamericana de Derechos Humanos (antesala de la Corte Interamericana de Derechos Humanos -Corte IDH-) por la falta de consulta previa, libre e informada respecto de las actividades extractivas que se desarrollan en sus territorios; así como por las amenazas de que son objeto.

Otro caso que da pie a la controversia en distintas aristas sociales, culturales, ambientales y, por su puesto, jurídicas es el relativo al Proyecto Conga, el cual, consiste en un proyecto de desarrollo productivo en minería de cobre, oro y plata por parte de una corporación constituida por varias empresas privadas denominadas en conjunto Yanacocha; el desarrollo fue proyectado a 19 años de extracción y procesamiento por lixiviación de los minerales en dos tajos a cielo abierto Chailhuagón y Perol-, ubicados a 73 kilómetros al noreste de la ciudad de Cajamarca en Perú; para lo cual, según la empresa, se utilizaría una extensión territorial de 2,000 hectáreas, que consistiría en el área de los tajos, depósito, procesamiento, depósito de suelo orgánico, reservorios de agua, instalaciones auxiliares y una estación eléctrica.

En 2008 comenzaron los estudios de la línea base ambiental para la elaboración del correspondiente Estudio de Impacto Ambiental (EIA), como requisito para el desarrollo del proyecto minero; así como la exploración de la zona para la elaboración de la ingeniería del proyecto en sus respectivas etapas. Cabe señalar que la minera señaló que en dicha zona ya existían 5 desarrollos minero-metalúrgicos de tajo abierto; entre ellos, uno propio denominado Maqui Maqui, por lo que, en su opinión la demarcación territorial ocuparía una parte dentro de una zona ya impactada. Así, Conga se proyectaba como un área más del complejo Yanacocha; no obstante, las comunidades rechazaron, tanto el EIA como las medidas de mitigación en el ámbito social y económica propuestas por el promovente; pues implicaba el desplazamiento comunitario a zonas urbanas (KNIGHT, 2010, p. 553).

Del análisis del caso se advierte una serie de inconsistencias y contradicciones en el EIA, que son parte toral de la argumentación en la defensa del territorio; como ejemplo, "el proyecto minero abarca 14, 336.643 hectáreas" (VILLA Y TORRES, 2017, p. 67), sin embargo, el EIA señala que se trata de aproximadamente, 2 mil hectáreas (KNIGHT, 2010). En lo que respecta a la afectación del agua subterránea y superficial, el EIA no lo detalla y la comunidad considera que el proyecto encierra el riesgo de degradación ambiental irreversible y un daño social significativo. Por tanto, se presentó una petición de fondo ante la Comisión Interamericana de Derechos Humanos (CIDH), a efecto de asegurar que el Estado peruano cumpla con sus obligaciones de respetar su derecho a ser consultadas y a definir sus propias prioridades de desarrollo. A la fecha el conflicto sigue sin resolverse.

Como prueba de la insuficiencia del derecho de los Estados-nación en cuanto al reconocimiento y garantía de los derechos colectivos, tenemos los pronunciamientos de la Corte Interamericana de Derechos Humanos (Corte IDH), que se ha caracterizado por una acción hermenéutica que da cabida a las particularidades jurídicas desde la otredad, lo cual, ha contribuido al empoderamiento de comunidades y pueblos indígenas mediante el reconocimiento de sus derechos, entre ellos, a la propiedad colectiva, a la vinculación existente entre ellos y sus tierras, territorios y recursos naturales (lo que involucra los derechos a un medio ambiente sano y a la salud); también se realizan acciones para hacer valer su derecho a ser consultados en relación con medidas legislativas y/o administrativas susceptibles de afectarles; ello con base en las disposiciones de la Convención Americana sobre Derechos Humanos y del Convenio 169.

Entre los casos resueltos por este tribunal, se encuentran: Comunidad Mayagna (Sumo) Awas Tingni vs. Nicaragua, Comunidad Indígena Yakye Axa vs. Paraguay, Comunidad Indígena Sawhoyamaxa vs. Paraguay, Saramaka vs. Surinam, Comunidad Indígena Xákmok Kásek Vs. Paraguay; Caso Pueblo Indígena Kichwa de Sarayaku vs. Ecuador (ANGLÉS, 2014b) y, el más reciente, Comunidades indígenas miembros de la Asociación Lhaka Honhat (Nuestra. Tierra) vs. Argentina es el primer asunto contencioso en la región que alude de forma expresa a la protección de los derechos a la propiedad comunitaria indígena, a un medio ambiente sano, a la alimentación 
y al agua; lo cual involucra el acceso al agua y a la alimentación, la recuperación de recursos forestales y de la cultura indígena.

Estos casos evidencian la necesidad de una concepción normativa plural cosmopolita y subalterna; ya que es necesario que las directrices para solucionar conflictos en tensiones seculares, como la lucha contrahegemónica, provengan de la base de las comunidades y pueblos, para que con el empleo de la red global se creen coaliciones y redes de acción a todos los niveles, de manera escalonada, que aporten visibilidad por la natural solidaridad que emerge de cualquier espacio del planeta; específicamente, tratándose de derechos colectivos y difusos, por lo que la lucha debe ser de base comunitaria y participativa hasta llegar al plano global, no a la inversa.

\section{CONCLUSIONES}

Los estudios críticos del derecho en América latina han colocado al pluralismo y al uso alternativo del derecho que contraviene al monismo del derecho moderno, como vías de acceso a un proceso emancipatorio tendiente a la solución de los crecientes y agravados conflictos socioambientales que se viven como resultado de la colisión de intereses, derechos y cosmovisiones que coexisten al interior de los Estados nación. Especial relevancia tienen las luchas de los pueblos y comunidades indígenas, quienes históricamente lidian, desde la asimetría del poder, con un entramado normativo y político excluyente, discriminatorio y homogeneizador.

De ahí, que sea dable acudir a una corriente crítica pluralista, en la que puedan encontrarse medios idóneos tendientes a garantizar el ejercicio efectivo y vigente de los derechos colectivos, entre ellos, el derecho a un medio ambiente sano; muestra de ello, son los casos mencionados que ponderan lo local sobre lo global, las costumbres emergentes desde la diversidad cultural frente al monismo hegemónico mestizo y lo gradual incluyente frente al avasallante formalismo universalista, característico de la ética liberal que permea al Derecho moderno europeo, impuesto en la región latinoamericana.

Es así que los mecanismos participativos comunitaristas deben considerar la proyección hacia un paradigma ético cada vez más holístico en lo ecológico que no jerarquice a los factores ambientales desde el antropocentrismo, sino que sea extensivo en cuanto a la valoración de los componentes ecosistémicos en búsqueda de una convivencia más equilibrada para todos los seres que cohabitan la región latina, de manera que el pluralismo jurídico constituye un insumo angular para la consideración de la otredad, como base y principio rector de las relaciones diversas.

La lucha desde la arena social contra el extractivismo y la opresión recolonial, así como la incorporación a ella de la noción ambiental, desde lo político y jurídico, es aún incipiente; además, la multidisciplinariedad la hace aún más compleja dado el monismo epistemológico que rige los paradigmas científicos y políticos en el mundo. Sin embargo, dicho óbice no debe acallar la voz y las movilizaciones en pos de la vida y la sustentabilidad planetaria. Por tanto, es invaluable revisar y criticar la configuración epistémica del derecho, desde una óptica trasformadora que centraliza la comunidad ecológica en su conjunto; pero asimismo hay que entender, que es una tarea que debe ser permanente, en constante reconstrucción para que, a partir de un proceso de diálogo, se logre expandir la visión progresista sobre la justicia distributiva que es desatendida en el ámbito de la protección de los derechos colectivos, esto incluye los que atañen a los pueblos y comunidades indígenas, pero no sólo a ellos, pues la garantía del derecho a un medio ambiente sano, alude a mantenimiento de las condiciones necesarias para el desarrollo de la vida en todas sus formas y regiones; incluso, considera la equidad entre las generaciones actuales y entre estas con las futuras. 


\section{BIBLIOGRAFÍA}

ÁNGEL ÁLVAREZ, J. A., “¿Quién gobierna en tiempos de globalización?”. In: ÁNGEL ÁLVAREZ, J. A., Filosofía y ética: deliberaciones sobre política y globalización. Bogotá: Ediciones Universidad Libre, 2011.

ANGLÉS HERNÁNDEZ, M., "El derecho al desarrollo y a los recursos naturales de los pueblos originarios de México en un contexto de discriminación y exclusión”. In: Sin Derechos. Exclusión y discriminación en el México Actual. México: UNAM, Instituto de Investigaciones Jurídicas, 2014a.

ANGLÉS HERNÁNDEZ, M., “Jurisprudencia interamericana. Acicate contra la discriminación y exclusión de pueblos originarios de México en relación con sus recursos naturales". Anuario Mexicano de Derecho Internacional. México: Vol. XIV, 2014a.

ANGLÉS HERNÁNDEZ, M., “Pobreza y desarrollo sostenible, alguna ¿relación/prelación?”. In: GODÍNEZ MÉNDEZ, W. A. y GARCÍA PEÑA, J. H. (Coords.), Derecho Económico y Comercio Exterior. 40 años de vida académica, homenaje a Jorge Witker. México: UNAM, Instituto de Investigaciones Jurídicas, 2015.

ANGLÉS HERNÁNDEZ, M.; LEYVA HERNÁNDEZ, A.; RUIZ CERVANTES, S., "Autonomía, derecho al desarrollo propio y derecho a la consulta". In: ANGLÉS HERNÁNDEZ, M. (coord.), Derechos humanos, pueblos indígenas y globalización. México: Comisión Nacional de los Derechos Humanos, 2017.

ANGLÉS HERNÁNDEZ, M.; GARCÍA ALTAMIRANO, E.; LÓPEZ BELDA, A., "Racionalidad legal, consulta ambiental y lucha de los pueblos indígenas por el desarrollo propio”. In GUTIÉRREZ RIVAS, R. y BURGOS MATAMOROS, M. (Coords.), Globalización, Neoliberalismo y Derechos de los Pueblos Indígenas en México. México: UNAM, Instituto de Investigaciones Jurídicas, 2020.

CALLICOTT, J. B., “En busca de una ética ambiental”. In: KWIATKOWSKA, T. e ISSA, J. (Comp.), Los caminos de la ética ambiental: una antología de textos contemporáneos. México: CONACYT, UAM, Plaza y Valdés, 1998.

CAPRA, F., Las conexiones ocultas, Barcelona, Anagrama, 2003.

CONEVAL, Medición de la Pobreza. Pobreza de Población Indígena. México: Comisión Nacional de Evaluación de la Política de Desarrollo Social, 2018.

DE SOUSA SANTOS,; RODRÍGUEZ GARAVITO, C., "Law, politics, and the subaltern in counter hegemonic globalization”. In: DE SOUSA SANTOS, B.; RODRÍGUEZ GARAVITO, C. (Eds.), Law and globalization from below: towards a Cosmopolitan legality, United Kingdom, University Press Cambridge, 2005.

DE SOUSA SANTOS, B., Refundación del Estado en América Latina: Perspectivas desde una epistemología del sur, Bogotá, Siglo del Hombre Editores, 2010.

DEZALY, Y.; GARTH, B., La internacionalización de las luchas por el poder. La competencia entre abogados y economistas por trasformar los estados latinoamericanos. México: UNAM, 
Instituto de Investigaciones Jurídicas, 2005.

FORERO RODRÍGUEZ, M. A., "Los fundamentos del pluralismo en la propuesta de Hannah Arendt”. In: ÁNGEL ÁLVAREZ, J. A., Filosofía y ética: deliberaciones sobre política y globalización. Colombia: Ediciones Universidad Libre, 2011.

GARCÍA VILLEGAS, M.o, "Ineficiencia del derecho y cultura del incumplimiento de reglas en América Latina". In: RODRÍGUEZ GARAVITO, C. (Coord.), El derecho en América Latina: un mapa para el pensamiento jurídico del siglo XXI. Buenos Aires: Siglo Veintiuno Editores, 2011.

INEEPB, Encuesta de Hogares 2016-2018. La Paz Bolivia: Instituto Nacional de Estadística del Estado Plurinacional de Bolivia, 2019.

KENNEDY, D., Libertad y restricción en la decisión judicial. El debate con la teoría crítica del Derecho (CLS). Bogotá: Siglo del Hombre Editores, 1999.

Knight Piesóld Consultores S.A y Minera Yanacocha S.R.L, Proyecto Conga informe final del Estudio de Impacto Ambiental. Perú, febrero de 2010.

KWIATKOWSKA, T., Controversias de la Ética Ambiental. México, Plaza y Valdés, 2009. LEMAITRE, J., "Law and globalism: law without the state as law without violence", en SARAT, A.; EWICK, P., The handbook of law and society. United Kingdom: John Wiley and Sons Inc., 2015.

LOWY, M., Ecosocialismo: la alternativa radical a la catástrofe ecológica capitalista. Madrid: Grupo Editorial Siglo Veintiuno, 2012.

MARTÍNEZ ALLIER, J., "Economía y ecología: Cuestiones fundamentales”, Pensamiento iberoamericano. Revista de Economía Política. Madrid: núm. 12, julio-diciembre 1987.

MIGNOLO, W., "La colonialidad a lo largo y a lo ancho: el hemisferio occidental en el horizonte colonial de la modernidad”. In: MIGNOLO, W., La colonialidad del saber: eurocentrismo y ciencias sociales. Perspectivas latinoamericanas. Buenos Aires: CLACSO, 2000.

MDSG, Índice de Pobreza Multidimensional. Nueva Guatemala de la Asunción: Ministerio de Desarrollo Social, 2018.

NAVA ESCUDERO, C., Ciencia, Ambiente y Derecho. México: UNAM, Instituto de Investigaciones Jurídicas, 2013.

PORTO MACEDO, R. J., "Derecho social, medio ambiente y desarrollo. Reflexiones en torno a un caso exitoso". In: RODRÍGUEZ GARAVITO, C. (Coord.), El derecho en América Latina: un mapa para el pensamiento jurídico del siglo XXI. Argentina: Grupo Editorial Siglo Veintiuno, 2011.

REGAN, T., "Derechos animales y ética medioambiental". In: HERRERA GUEVARA, A., De animales y hombres: "Studia Philosophica", Oviedo, Universidad de Oviedo, 2007.

RIECHMANN, J., Ética extramuros. Madrid: Universidad Autónoma de Madrid, 2016. 
RODRÍGUEZ GARAVITO, C.; ARENAS, L. C., "Indigenous rights, transnational activism, and legal mobilization: the struggle of the U'wa people in Colombia”. In: DE SOUSA SANTOS, B.; RODRÍGUEZ GARAVITO, C. (Eds.), Law and globalization from below: towards a Cosmopolitan legality. United Kingdom: University Press Cambridge, 2005.

RODRÍGUEZ GARAVITO, C., Etnicidad.gov, los recursos naturales, los pueblos indígenas y el derecho a la consulta previa en los campos sociales minados, Bogotá, Colección Dejusticia, 2012.

RODRÍGUEZ, C.A.; GARCÍA VILLEGAS, M., "Derecho y sociedad en América Latina: propuesta para la consolidación de los estudios jurídicos críticos”. In: RODRÍGUEZ, C. A.; GARCÍA VILLEGAS, M. (Eds.), Derecho y Sociedad en América Latina: Un debate sobre los Estudios Jurídicos Críticos. Bogotá: Martha Rojas Publicaciones-Instituto Latinoamericano de Servicios Legales Alternativos, 2003.

SINGER, P., Liberación animal. Madrid: Trotta, 1999.

WOLKMER, A.C., Pluralismo Jurídico: fundamentos de una nueva cultura del Derecho. 2a. ed. Madrid: Dykinson, 2018.

YRIGOYEN FAJARDO, R., "El horizonte del constitucionalismo pluralista: del multiculturalismo a la descolonización”. In: RODRÍGUEZ GARAVITO, C. (Coord.), El derecho en América Latina: un mapa para el pensamiento jurídico del siglo XXI. Argentina: Grupo Editorial Siglo Veintiuno, 2011.

YRIGOYEN FAJARDO, R., "Hitos del reconocimiento del pluralismo jurídico y el derecho indígena en las políticas indigenistas y el constitucionalismo andino". In: BERRAONDO, M. (Coord.) Pueblos Indígenas y Derechos Humanos. Bilbao: Universidad de Deusto, 2006.

VILLA, Z.; TORRES, M., "Caso Conga: pueblos originarios de Cajamarca resisten ante megaproyecto minero". Revista Alertanet en litigio estratégico y formación de pueblos indígenas. Lima, año 2, núm. 1, marzo 2017. 